\title{
Seismic Vulnerability Assessment and Fragility Analysis of Pre-Code Masonry Buildings in Portugal
}

\section{Vasco Bernardo ( $\nabla$ vbernardo@lnec.pt )}

National Laboratory of Civil Engineering: Laboratorio Nacional de Engenharia Civil https://orcid.org/0000-0002-5071-8155

\section{Alfredo Campos Costa}

Laboratorio Nacional de Engenharia Civil

\section{Paulo Candeias}

Laboratorio Nacional de Engenharia Civil

\section{Aníbal Costa}

Universidade de Aveiro Departamento de Engenharia Civil

\section{Research Article}

Keywords: pre-code masonry buildings, fragility analysis, seismic vulnerability assessment, seismic safety

Posted Date: May 18th, 2021

DOI: https://doi.org/10.21203/rs.3.rs-476957/v1

License: (c) (i) This work is licensed under a Creative Commons Attribution 4.0 International License. Read Full License 


\section{Abstract}

Despite the fact that in recent years Portugal has not seen the occurrence of high-magnitude earthquakes, it remains threatened by these events due to its geographic location. Since the 1960s, reinforced concrete has been the most used material for new constructions, however the historic urban centers are dominated by old unreinforced masonry (URM) buildings which techniques and construction materials have evolved since the Great Lisbon earthquake that occurred in 1755 with a magnitude around 8.5. Given the presence of these buildings in areas of significant seismicity, a comprehensive research is needed to assess the seismic risk and define mitigation policies. This kind of studies are often supported by empirical methods and based on expert judgment due to the high variability of the building stock and lack of information. The main purpose of this work is: i) to provide analytical fragility curves, supported by nonlinear static analysis, for the entire population of old masonry buildings, built before the introduction of the first design code for building safety against earthquakes (RSSCS) in 1958; ii) define vulnerability curves to be used by the technical community for seismic risk assessment of pre code URM buildings. The characterization of the building stock geometry and material properties is based on the previous information collected, which was useful to define representative archetypes and typologies.

\section{Full Text}

This preprint is available for download as a PDF.

\section{Figures}




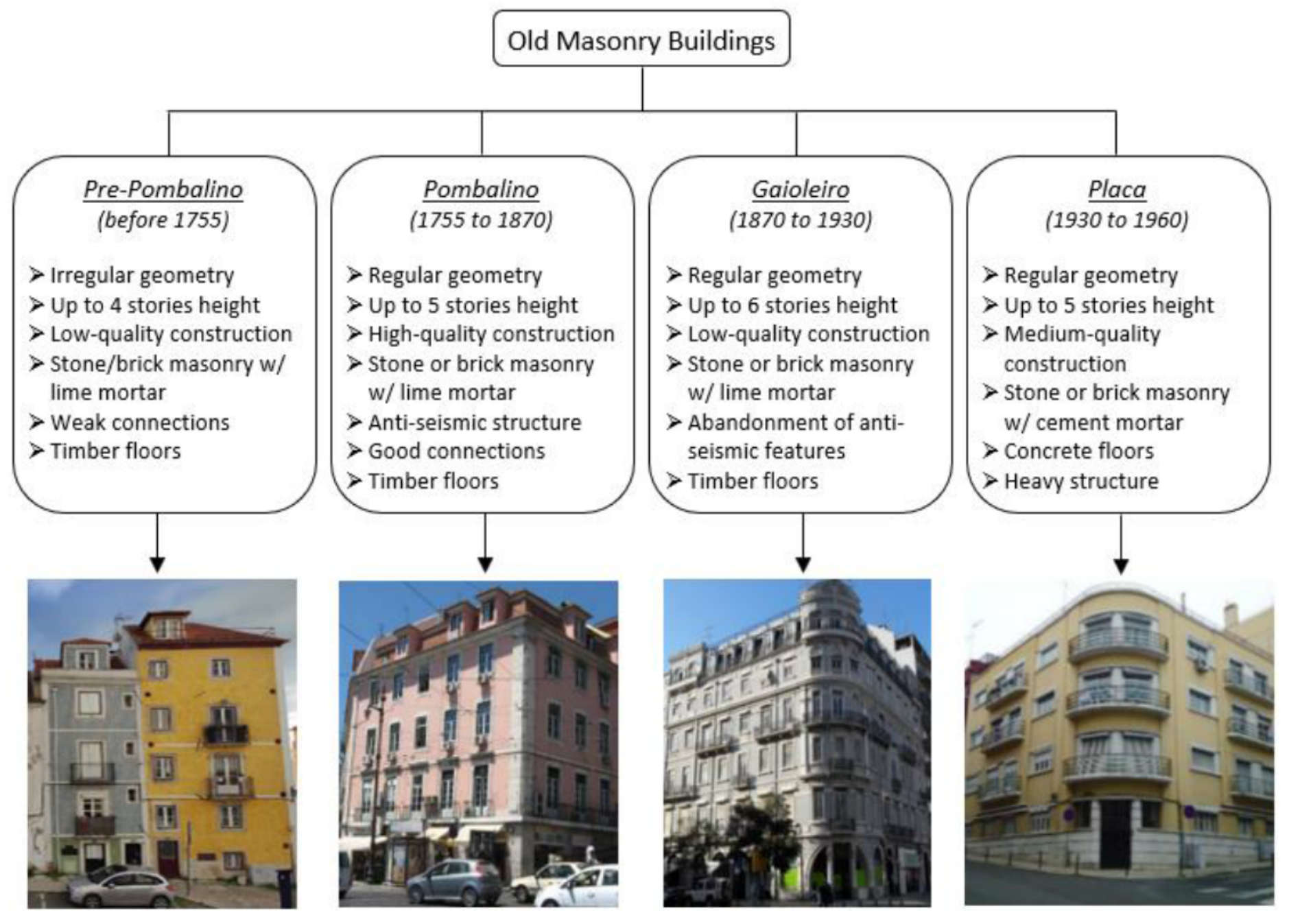

Figure 1

Main features of old masonry buildings 

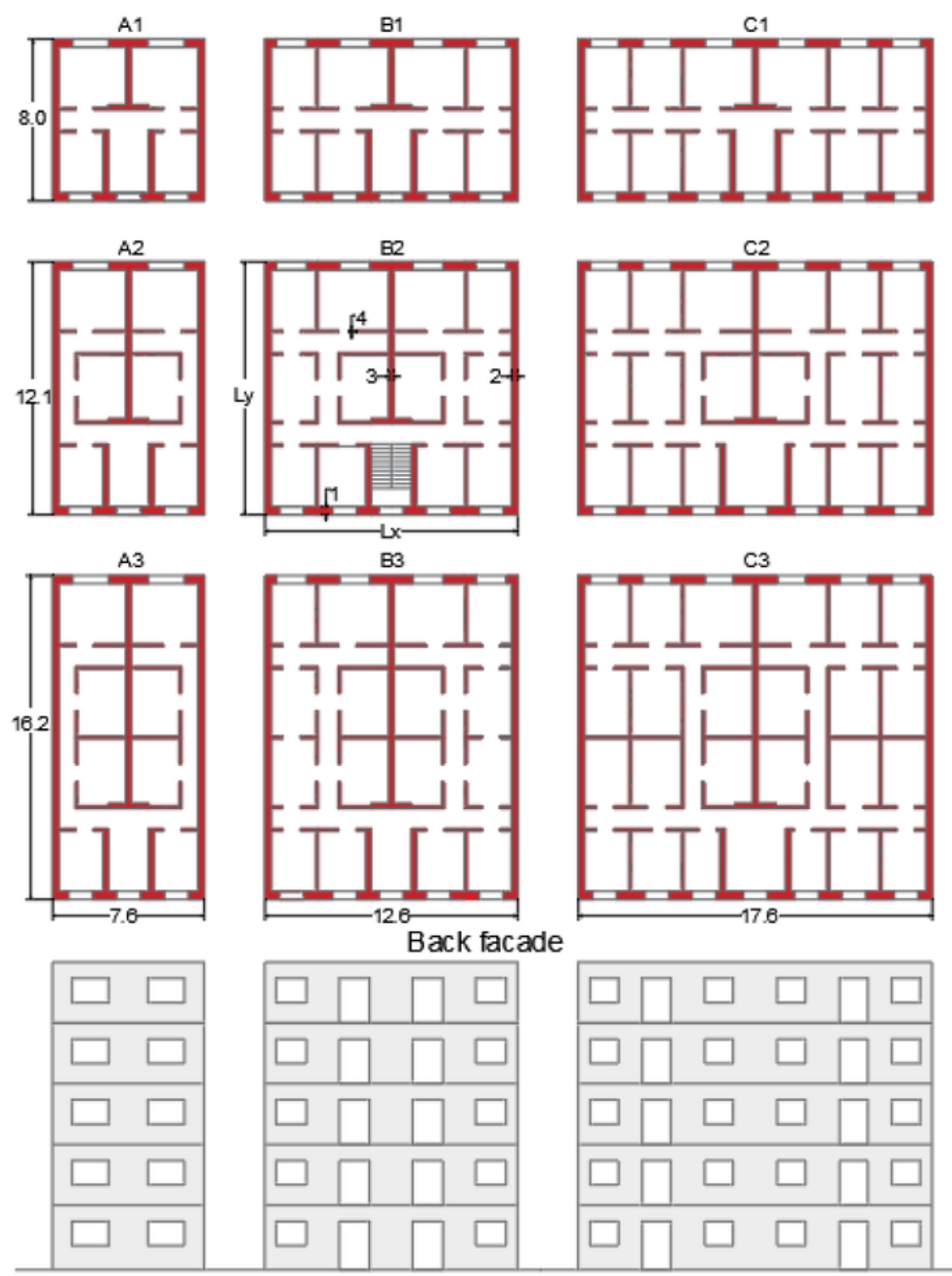

Front facade
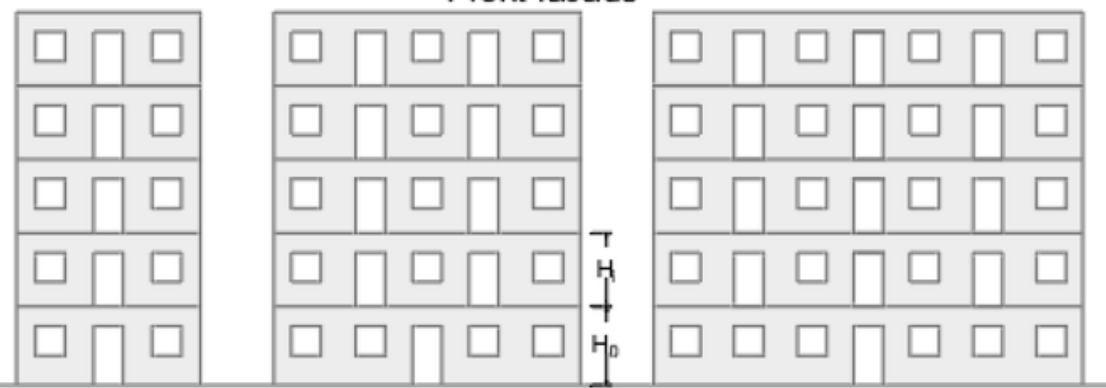

Figure 2

Archetypes adopted to represent the population of old masonry buildings in Portugal 

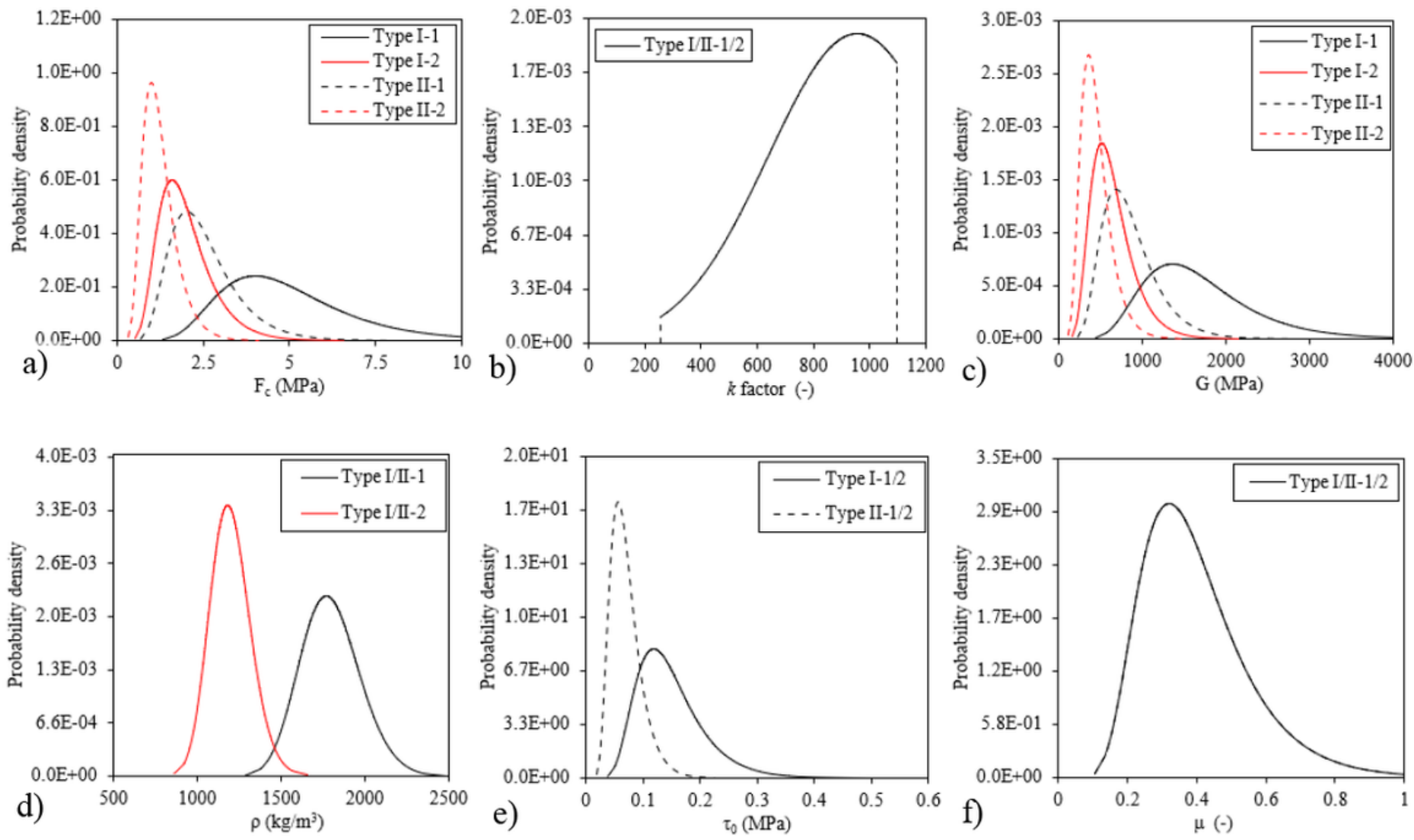

Figure 3

Mechanical properties generated: a) compressive strength; b) $\mathrm{K}$ factor; c) shear modulus; d) material density; e) cohesion; f) friction coefficient 
a)

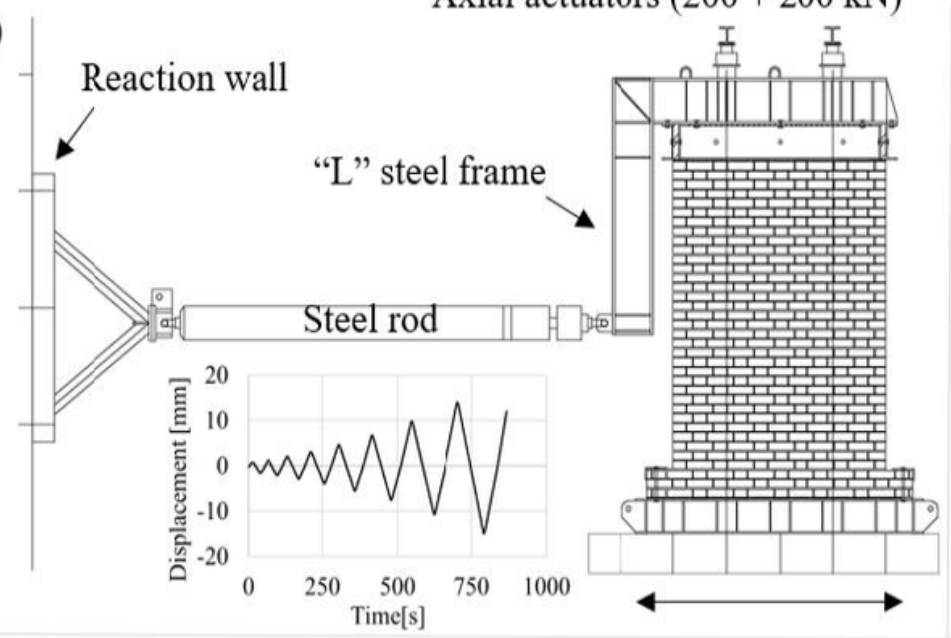

c)

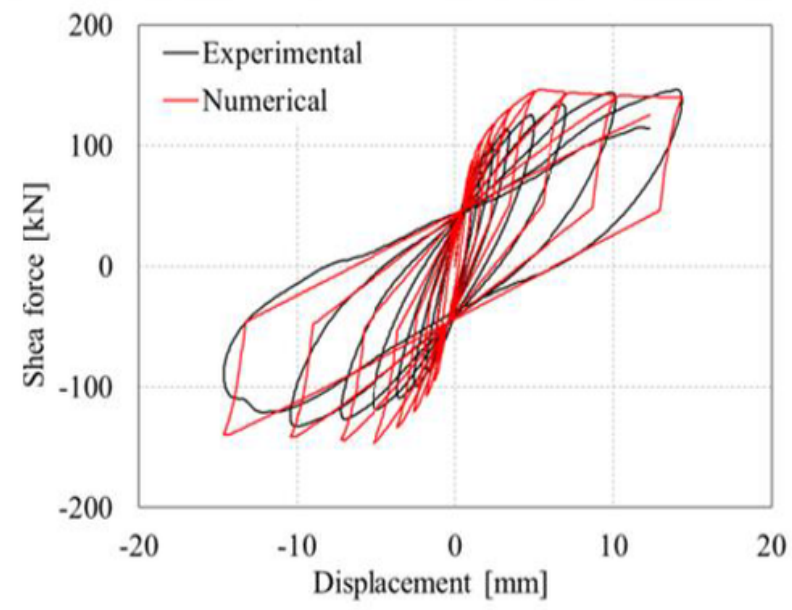

b)

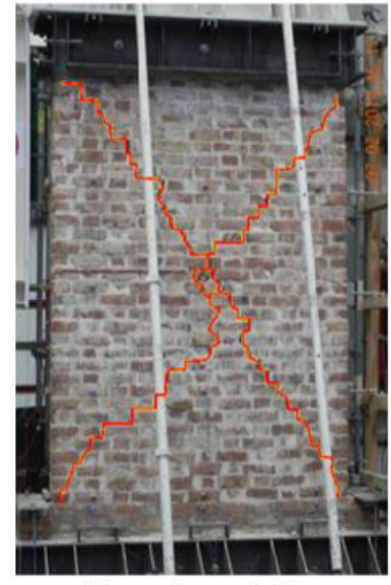

Experimental

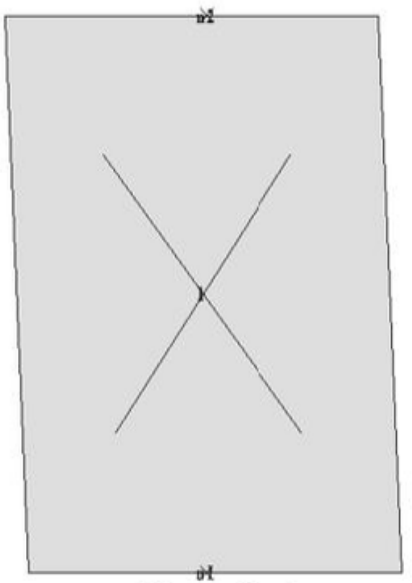

Numerical

d)

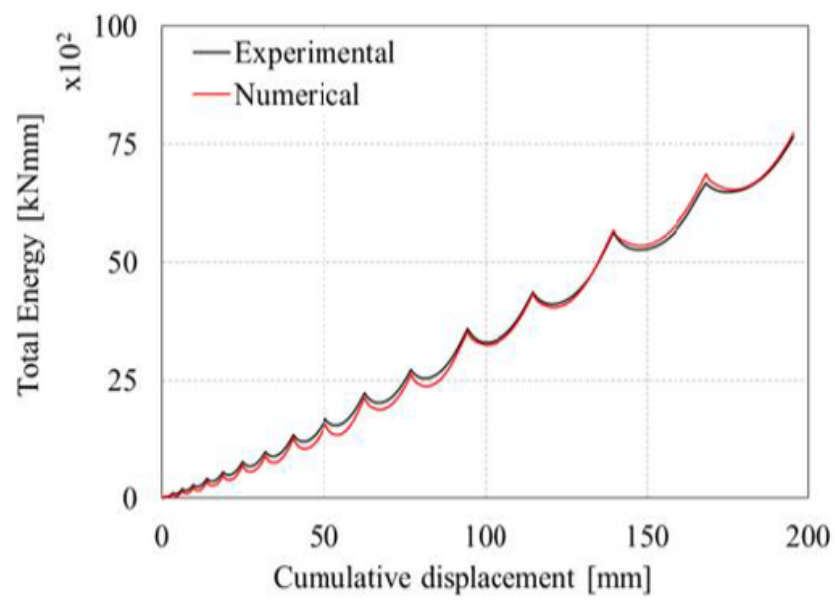

Figure 4

Macroelement validation: a) setup of experimental cyclic test; b) damage pattern (experimental and numerical damage pattern representation); c) and d) comparison of experimental and numerical cyclic force-displacement curve and hysteretic total energy dissipation, respectively 

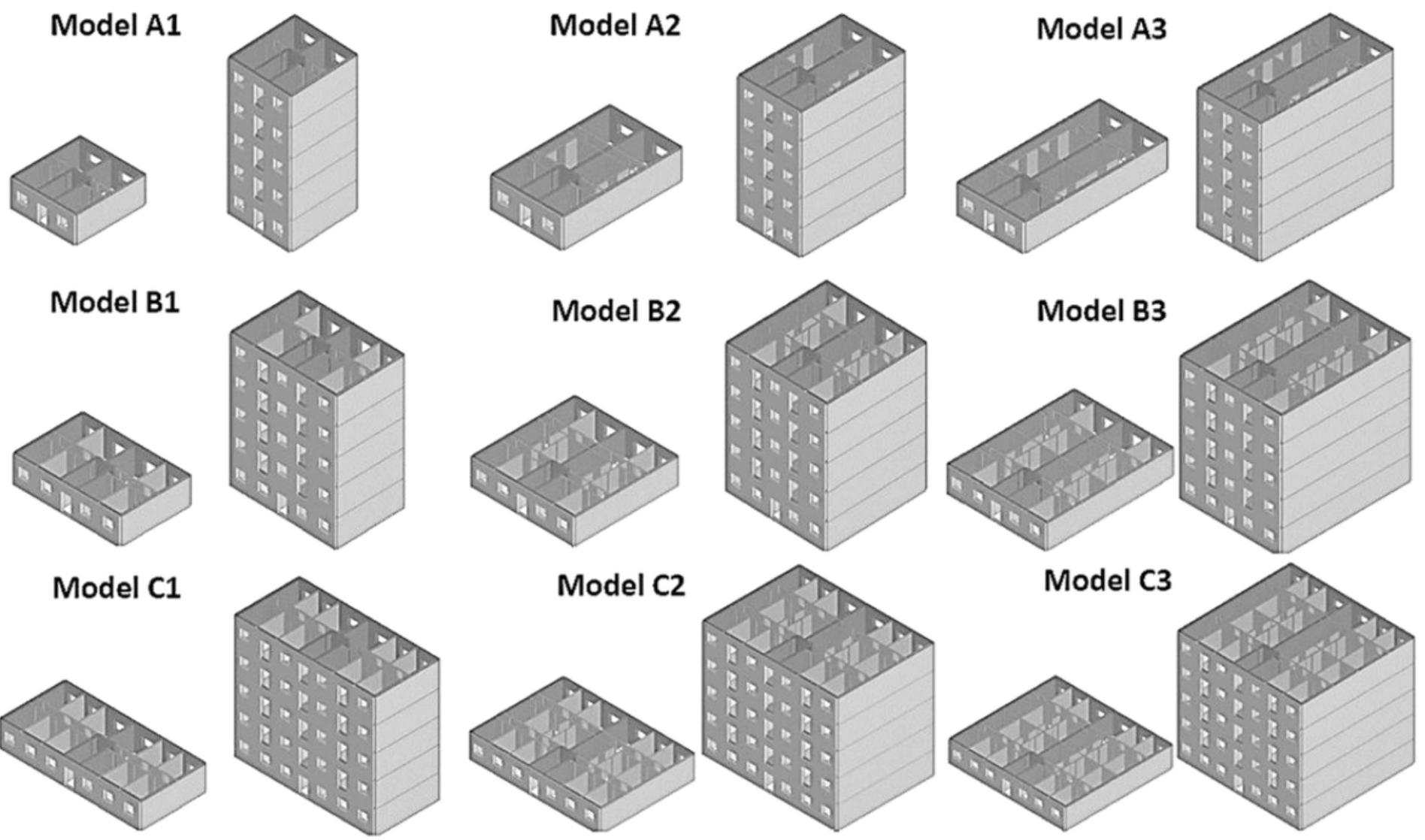

Figure 5

Archetypes of masonry old buildings modelled in Tremuri

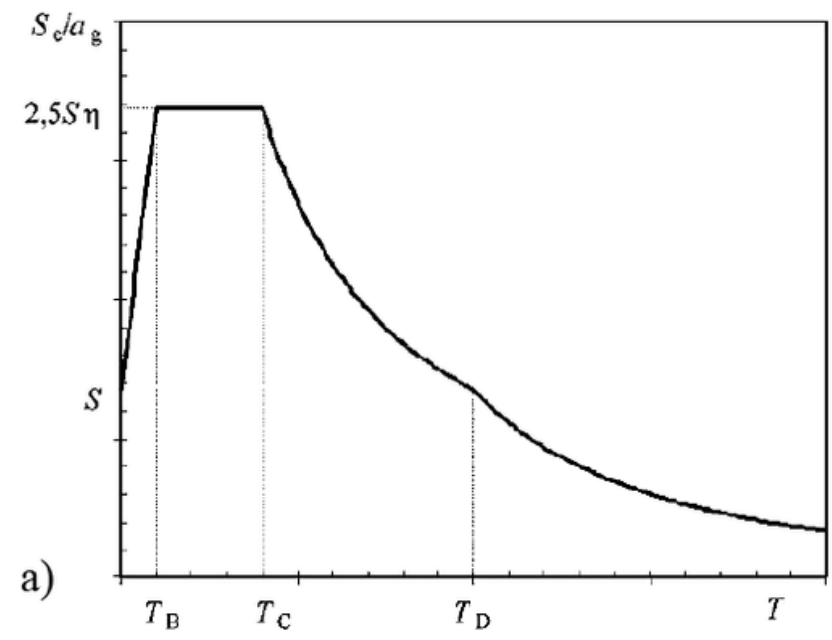

b)

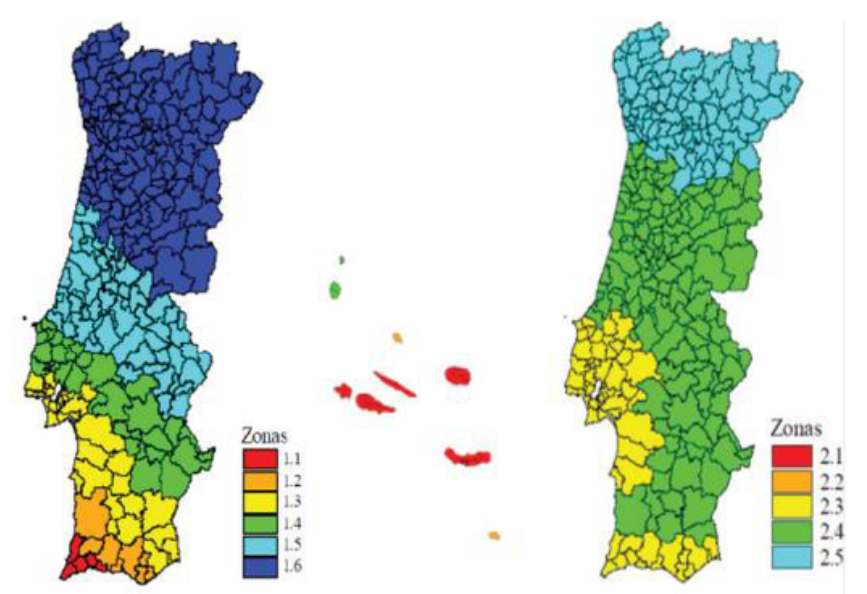

Figure 6

Seismic action for Portugal: a) horizontal elastic response spectrum in EC8 format; b) seismic zonings I and II $\neg$ interplate scenario and intraplate scenario, respectively (CEN 2004) Note: The designations employed and the presentation of the material on this map do not imply the expression of any opinion 
whatsoever on the part of Research Square concerning the legal status of any country, territory, city or area or of its authorities, or concerning the delimitation of its frontiers or boundaries. This map has been provided by the authors.
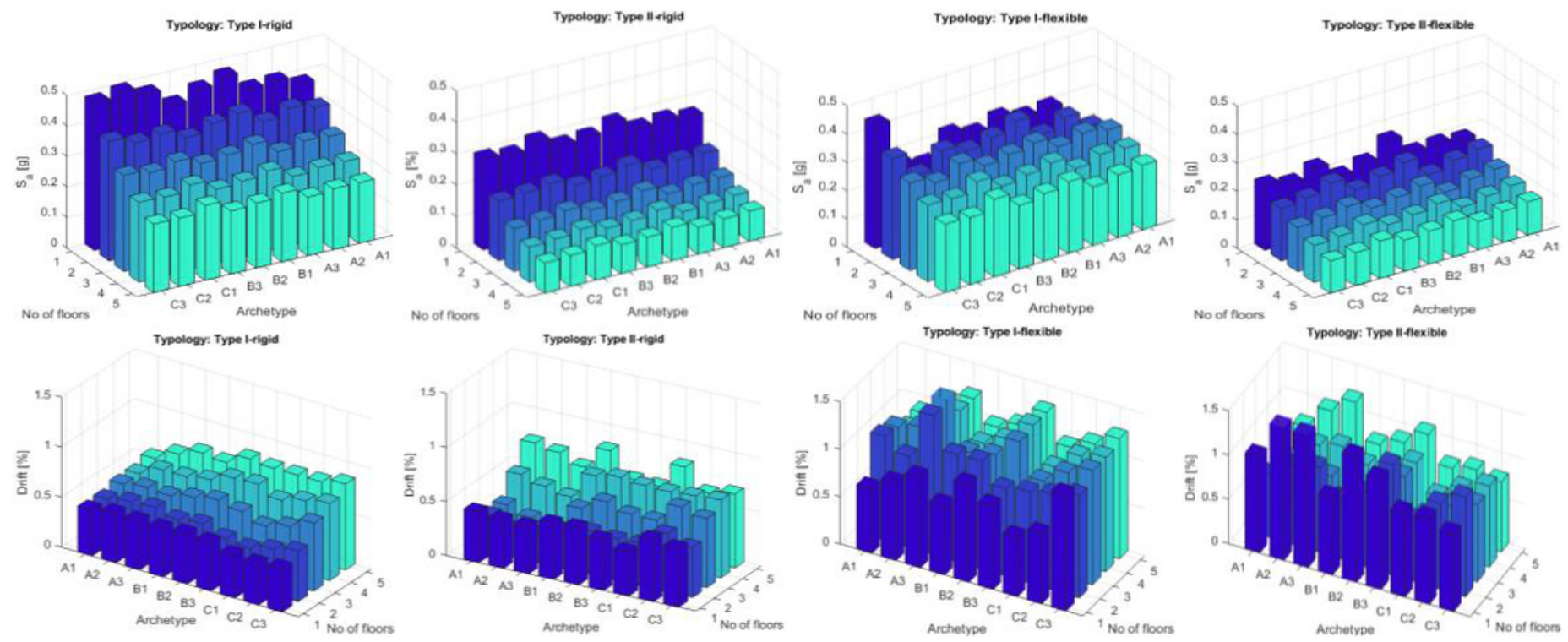

Figure 7

Median values for maximum spectral acceleration (top row) and interstorey drift (bottom row) 

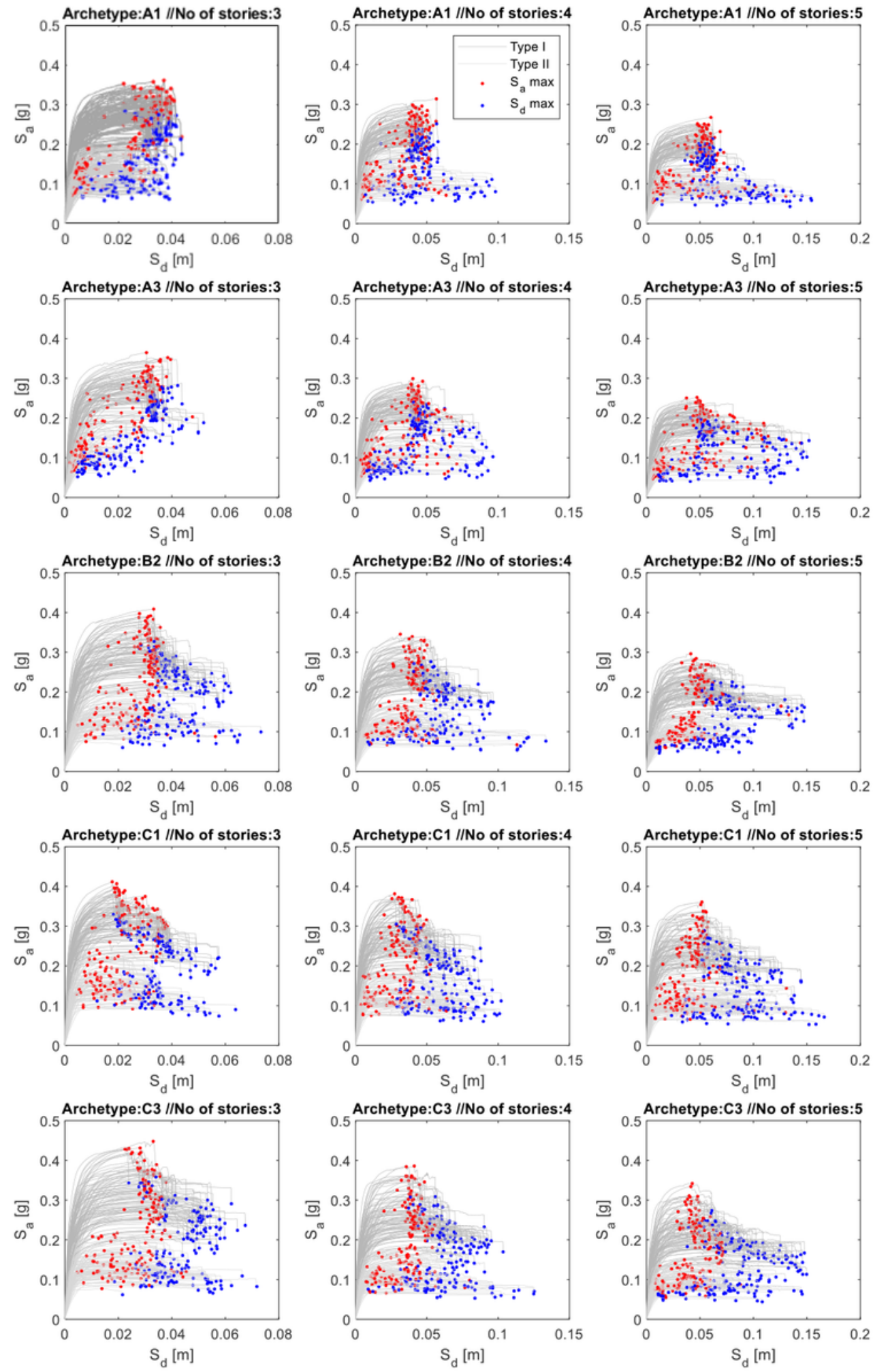

\section{Figure 8}

Capacity curves for archetypes $\mathrm{A} 1, \mathrm{~A} 3, \mathrm{~B} 2, \mathrm{C} 1$, and $\mathrm{C} 3$, with 3,4 and 5 stories heigh and rigid floors 

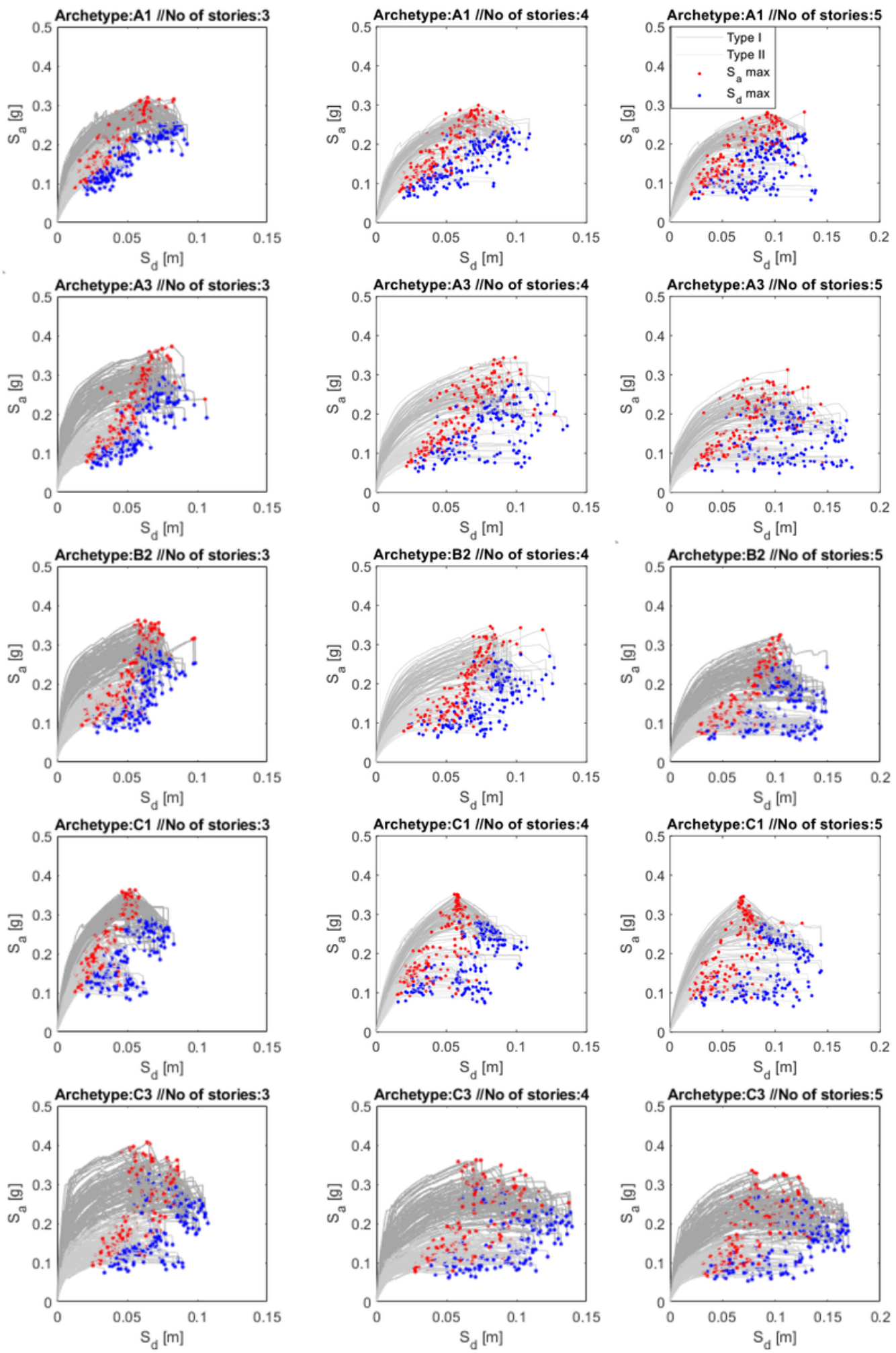

\section{Figure 9}

Capacity curves for archetypes A1, A3, B2, C1, and C3, with 3, 4 and 5 stories heigh and flexible floors 

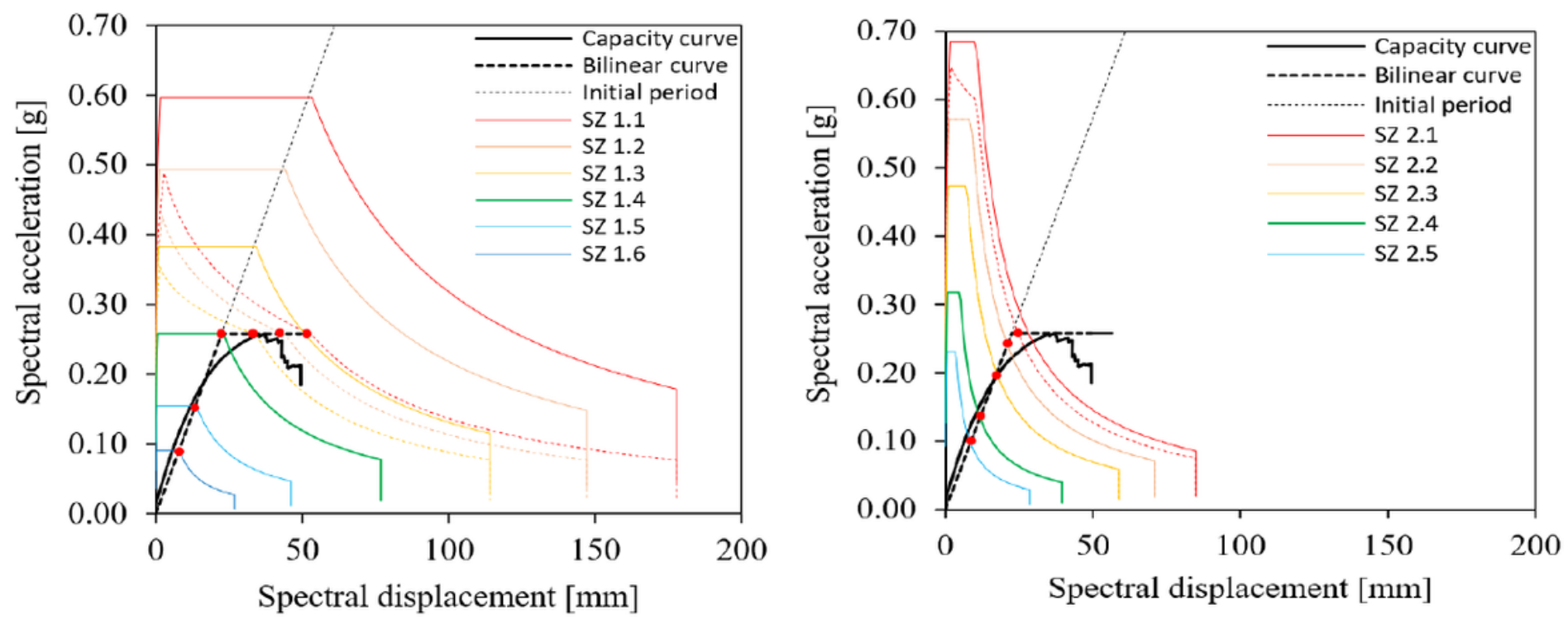

Figure 10

Seismic performance (red point) for a building with four stories, archetype B2 and type I-rigid typology, considering 308-years return period, soil type B and all seismic zones defined for Portugal
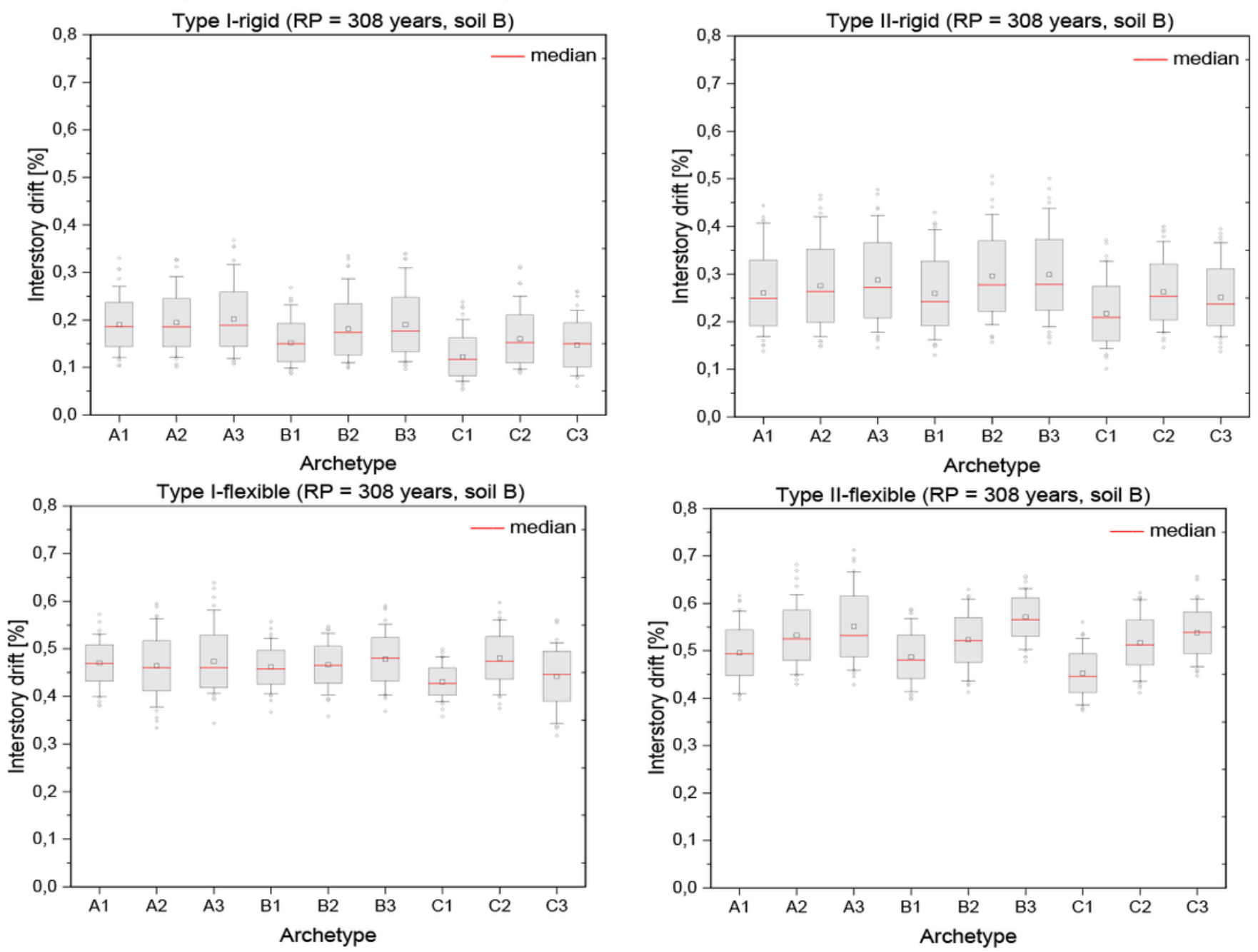


\section{Figure 11}

Seismic response in terms of interstorey drift for buildings with four stories high, 308-years return period, soil type B and seismic zone 1.3
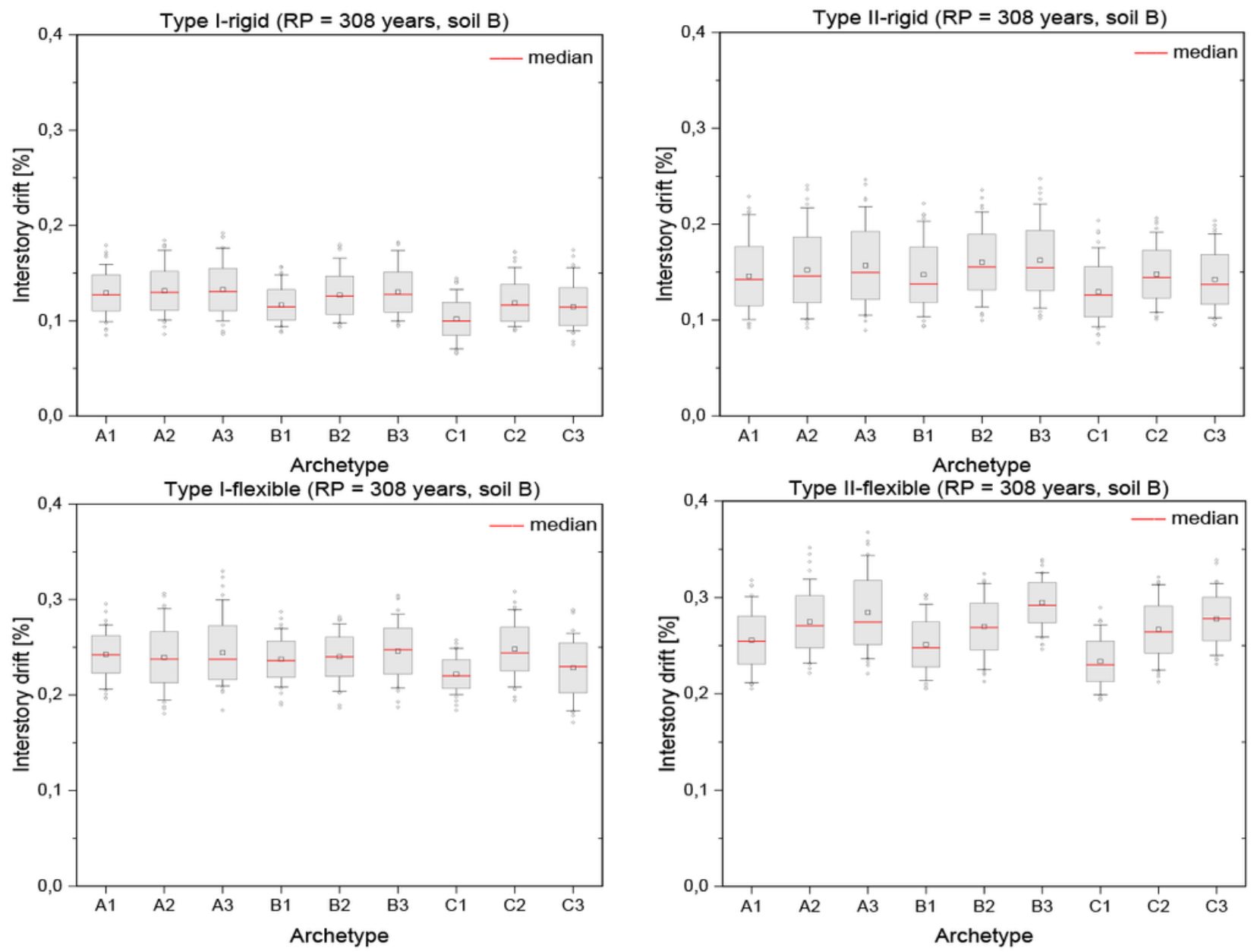

Figure 12

Seismic response in terms of interstorey drift for buildings with four stories high, 308-years return period, soil type B and seismic zone 2.3 

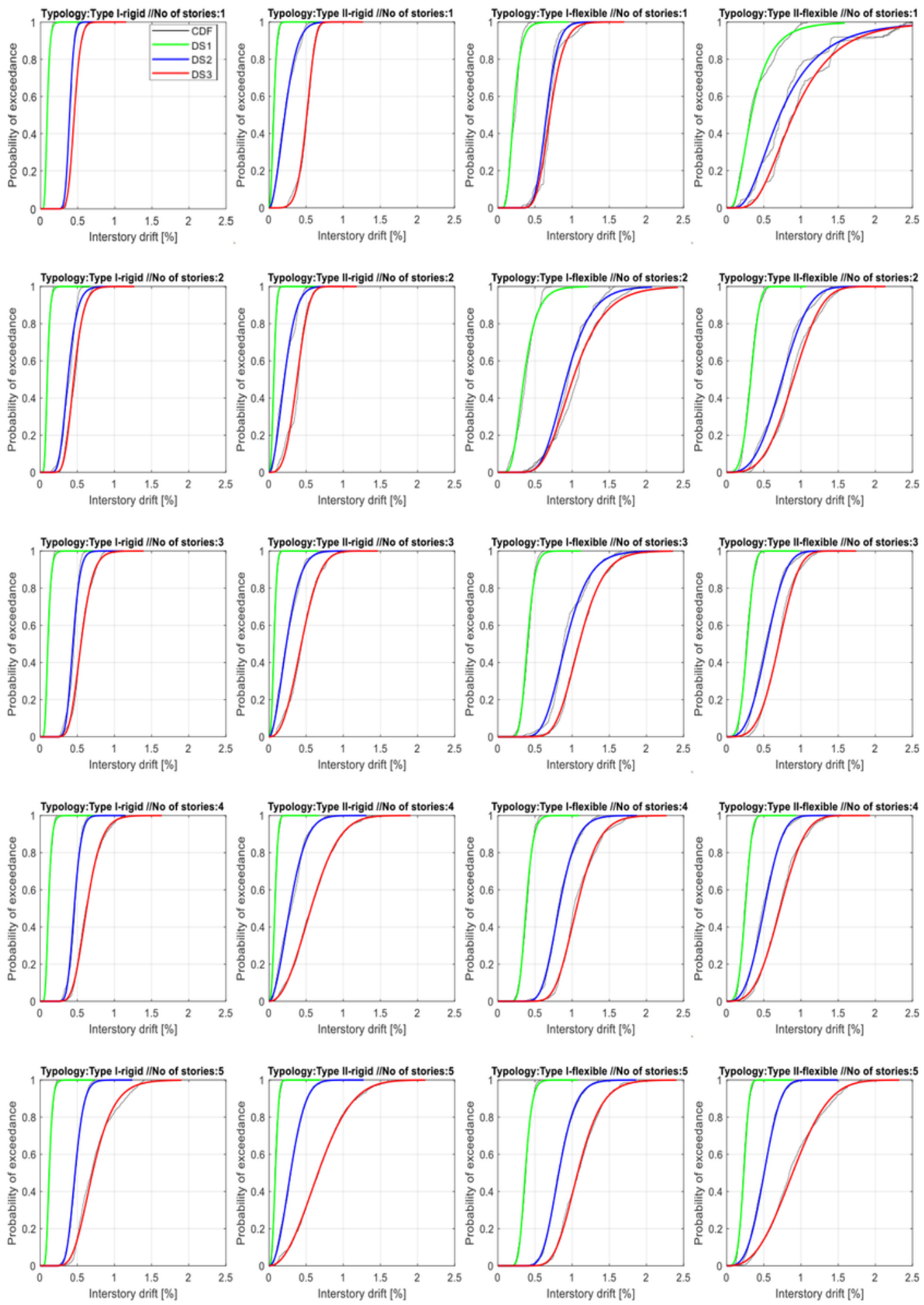

\section{Figure 13}

Fragility curves for archetypes grouped by number of floors, typology and type of floor (rigid and flexible) 

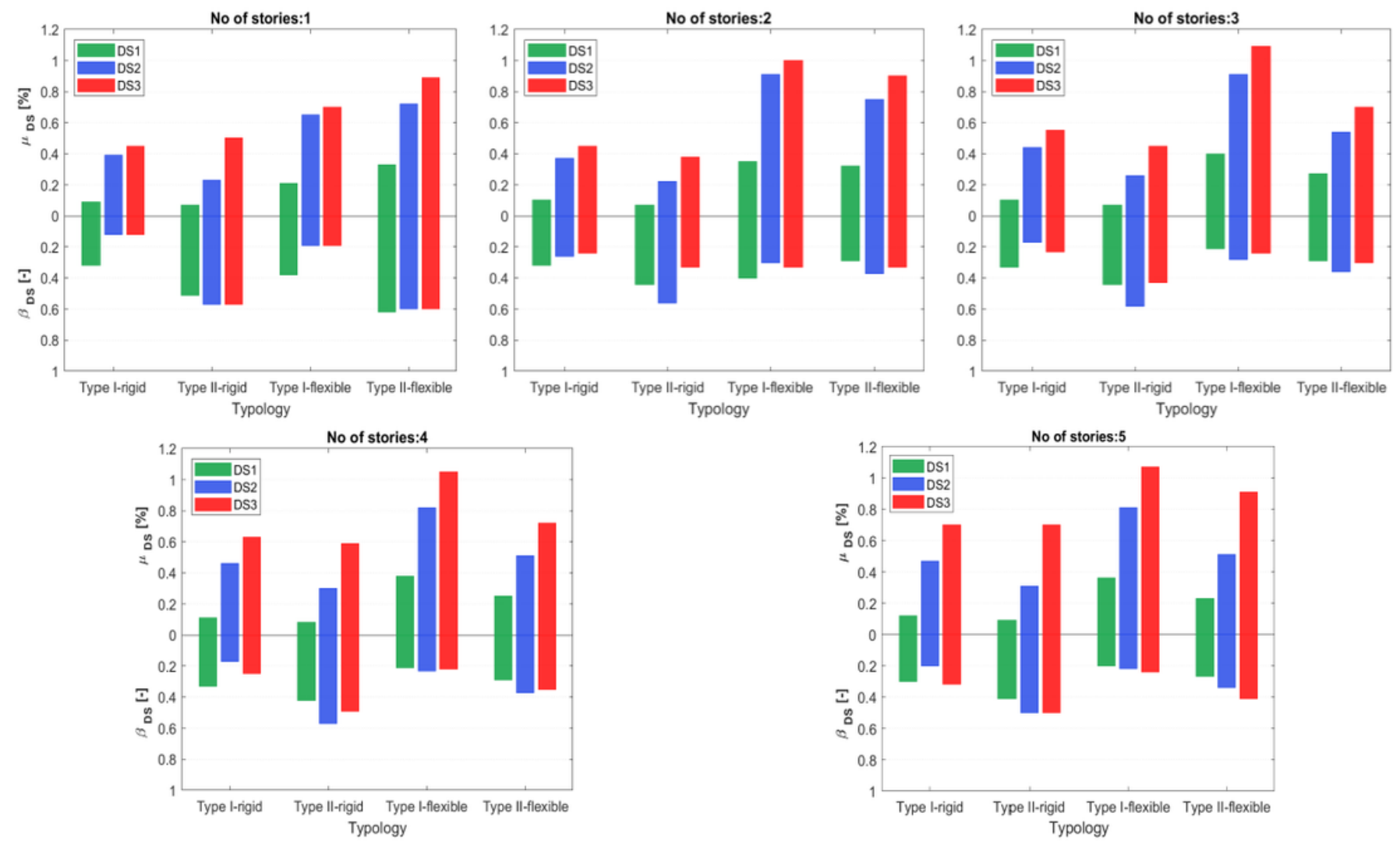

Figure 14

Mean values and dispersion proposed to characterize the fragility by number of floors and typology 
Typology: Type I-rigid // No of stories: 4

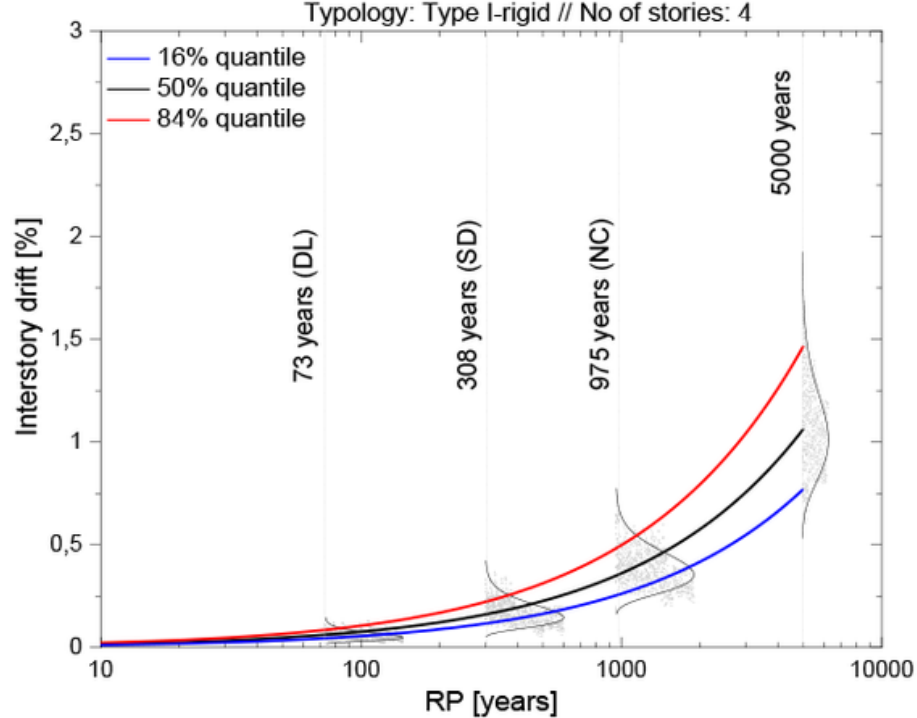

Typology: Type I-flexible // No of stories: 4

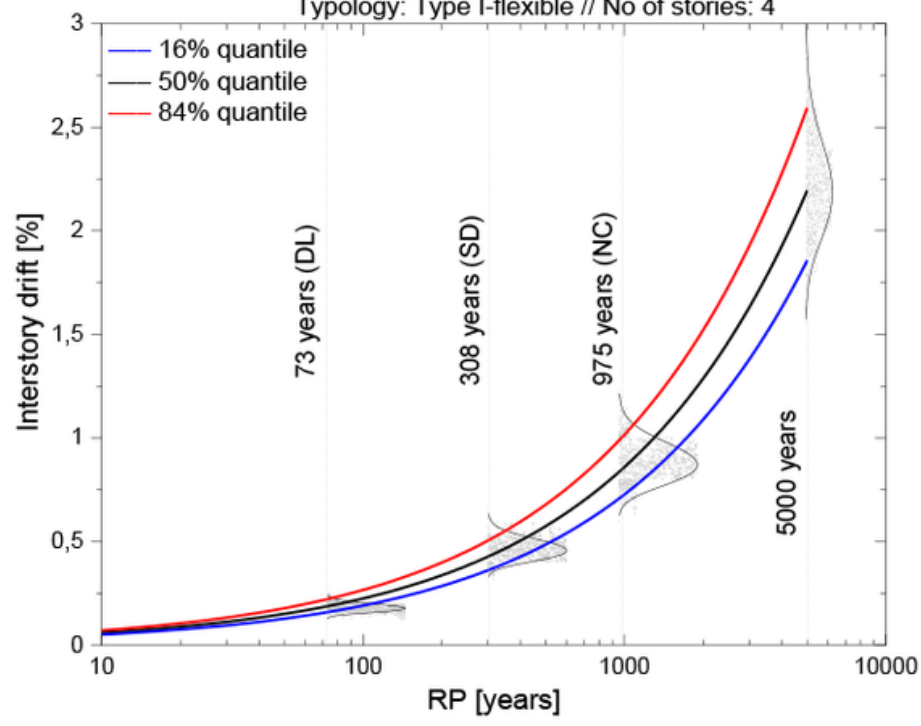

Typology: Type II-rigid // No of stories: 4

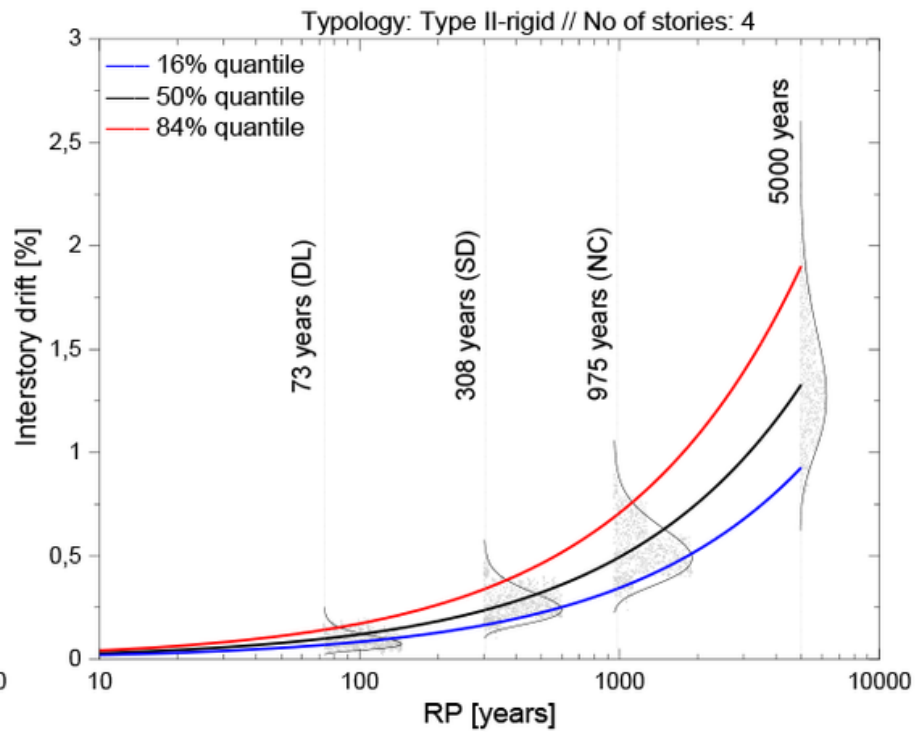

Typology: Type Il-flexible // No of stories: 4

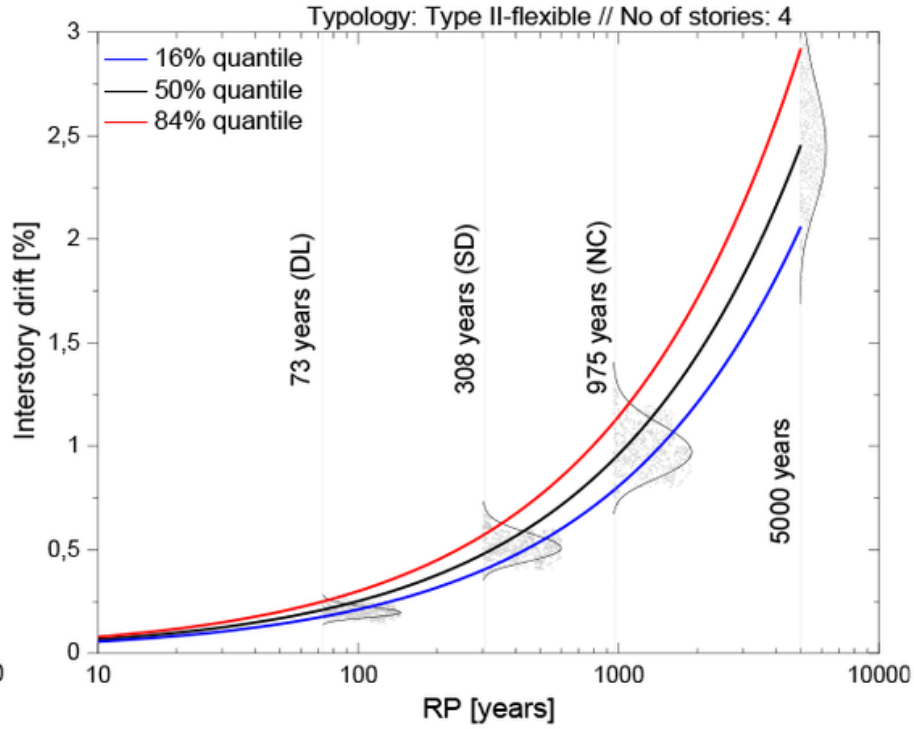

Figure 15

Vulnerability curves archetypes grouped, four stories high, soil type B and seismic zone 1.3 

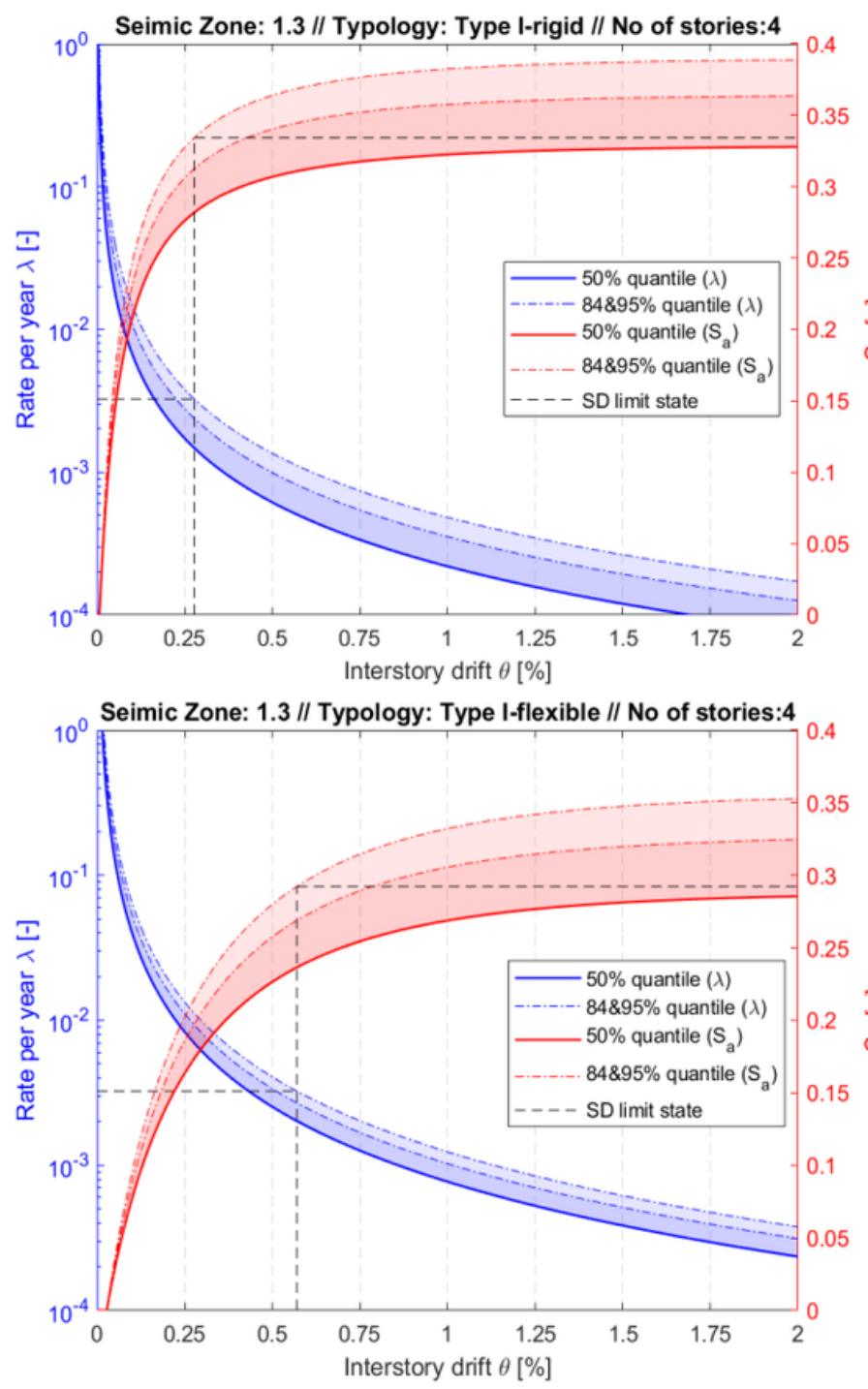
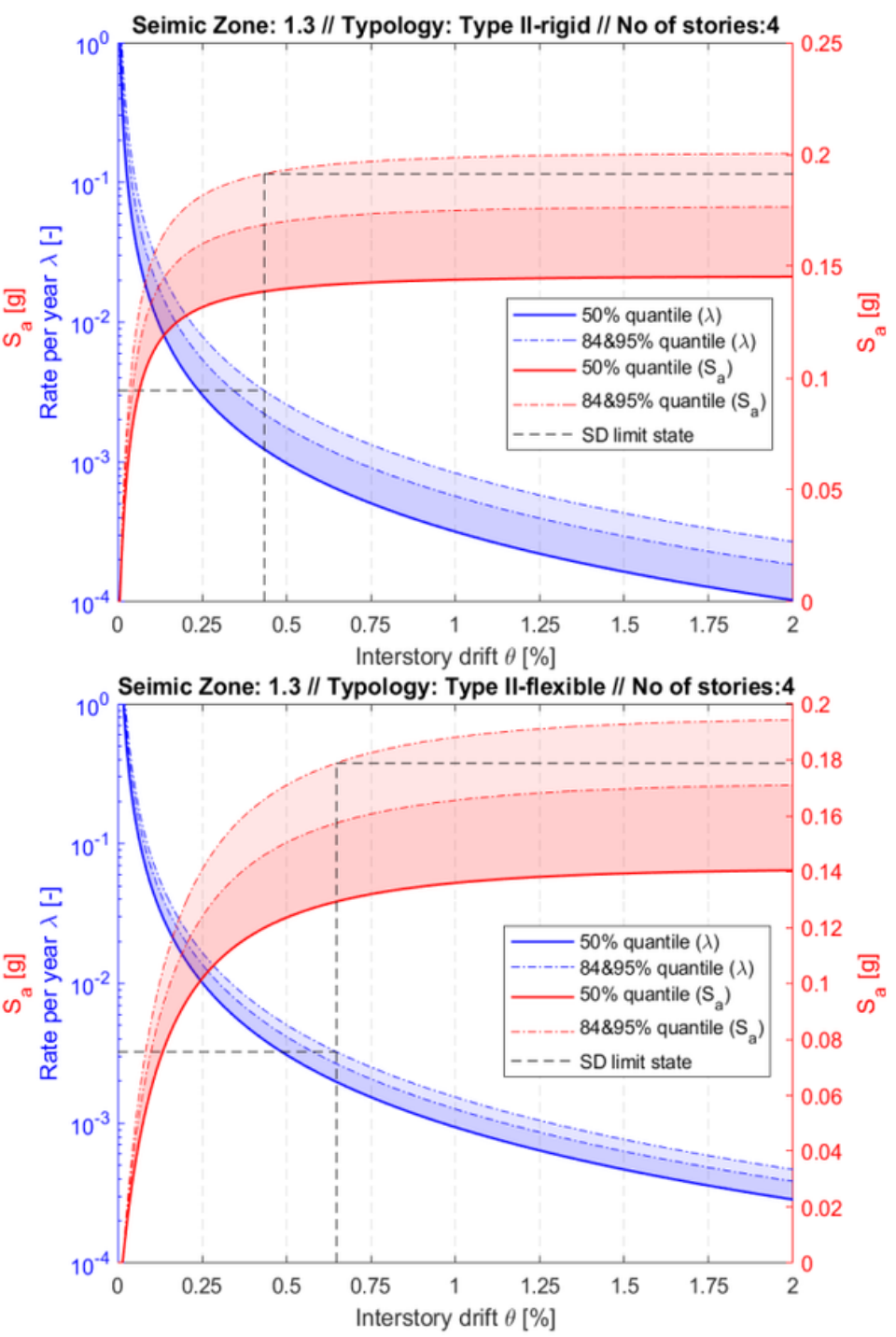

Figure 16

Seismic demand for buildings with four stories high, soil B, and seismic zones 1.3 

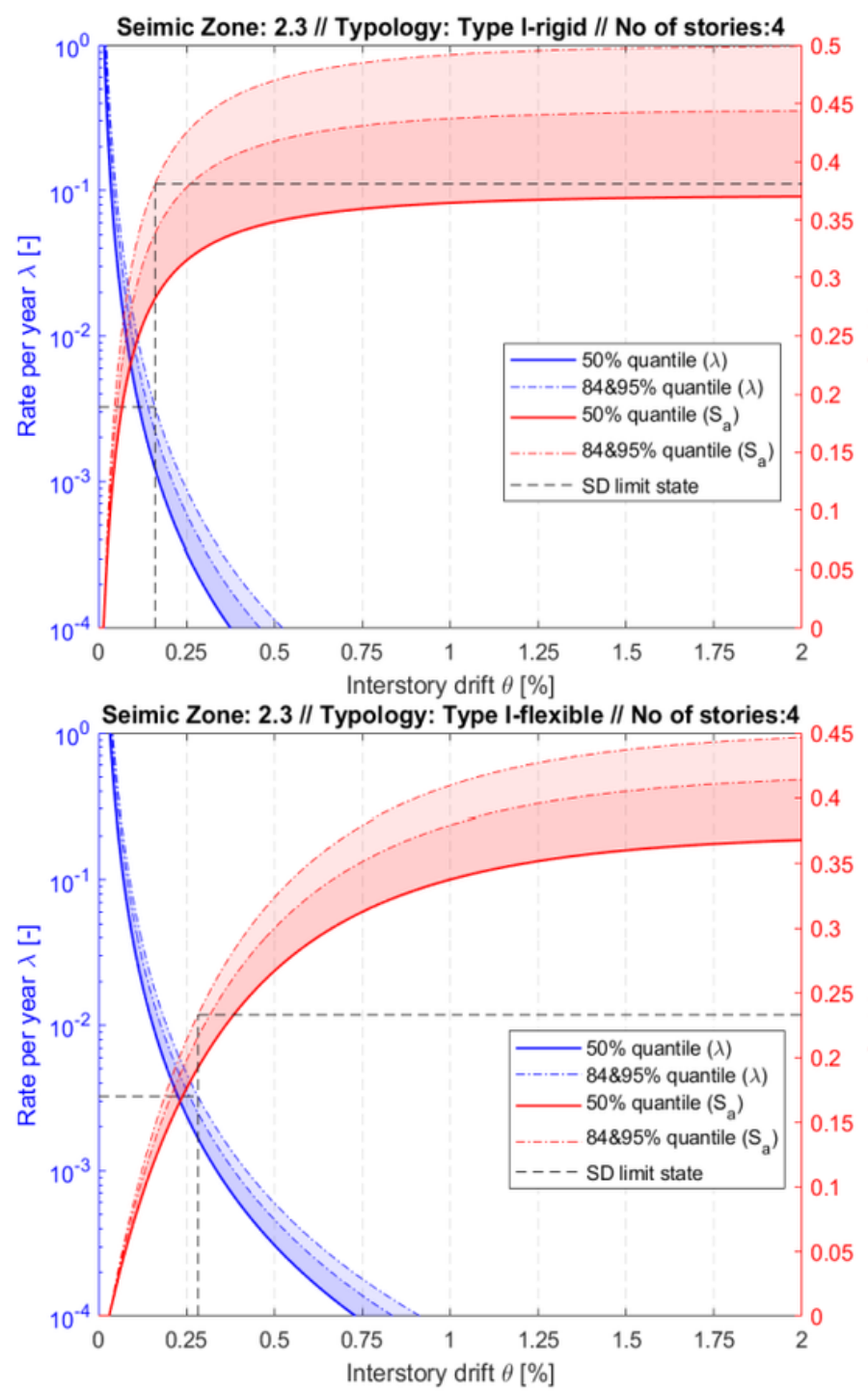

Seimic Zone: 2.3 // Typology: Type II-rigid // No of stories:4
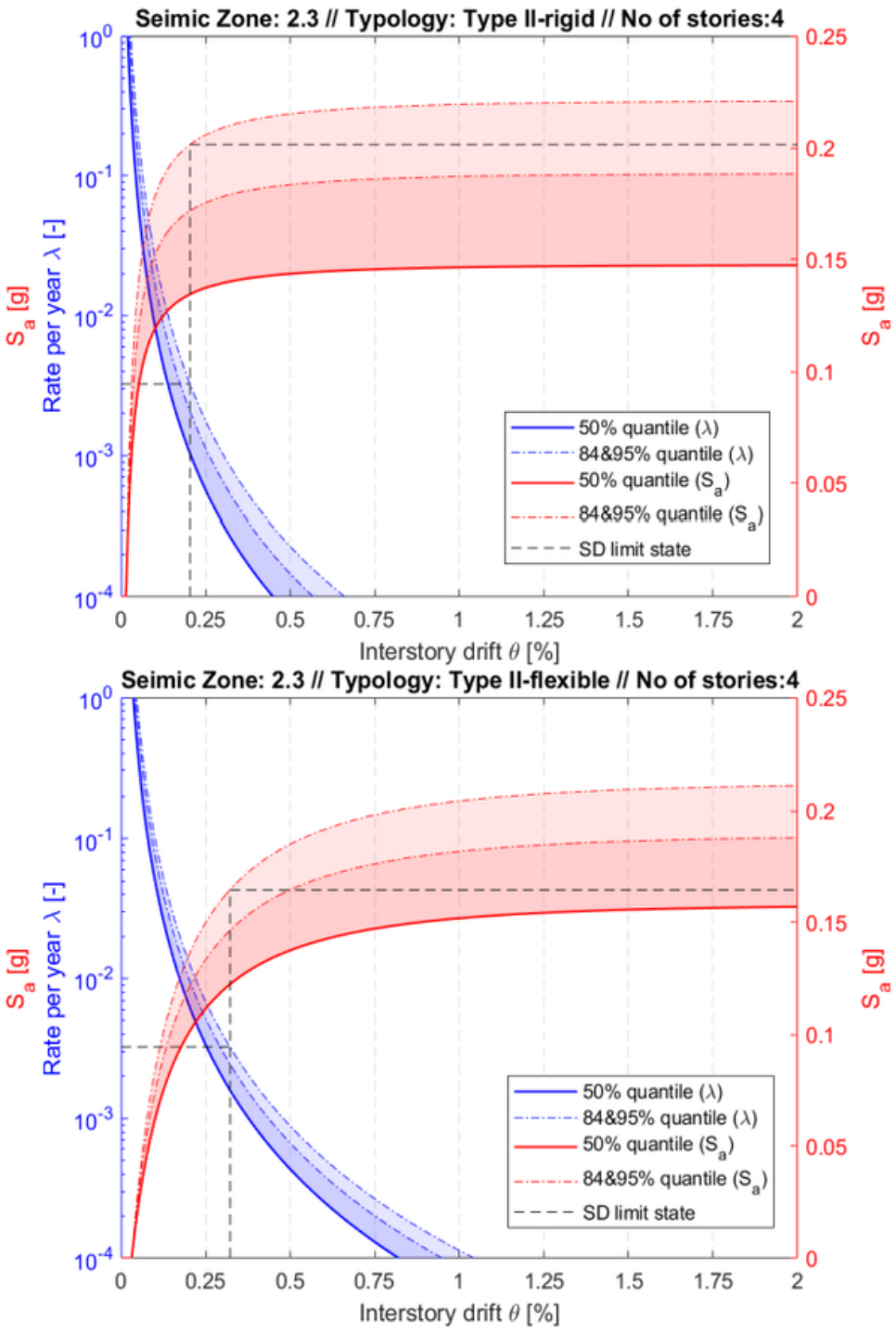

Figure 17

Seismic demand for buildings with four stories high, soil B, and seismic zones 1.3 